\title{
DEN TEOLOGISKA HOLOCAUSTLITTERATUREN
}

\author{
Karl-Johan Illman
}

Ábo

\section{Holocaust-temat inom judisk teologi}

\section{Inledning}

Beteckningen holocaust, heloffer, brännoffer, förknippas väl inom en bredare allmänhet med den film - i sin tur baserad på Gerald Greens roman $^{1}$ - med samma namn, som väckte ett enormt uppseende för ett par år sedan först $i$ USA och sedan i Europa. Termen användes om nazitidens utrotning av den europeiska judenheten redan tidigare inom historieforskningen, litteraturen och teologin. Det är betecknande för detta tema, att det först på sistone har kunnat bli föremål för vad man kunde kalla en "teologisk reflexion«. Det första decenniet efter krigsslutet ägnades åt domstolsförfaranden, statistiska beräkningar av katastrofens omfattning och preliminära beskrivningar av det skedda. Under det andra decenniet började man samla litteratur i form av dagböcker (t.ex. Chaims Kaplans "Dödens dokument«) och de första mer eller mindre självbigrafiska arbetena såg dagens ljus, såsom Elie Wiesels »Natten * och André Schwartz-Barts "Den siste av de rättfärdiga ${ }^{2}$. Här har vi också de första försöken till interpretation av det skedda. Först under det tredje decenniet börjar man på allyar dra slutsatser. Man hävdar, att hur viktigt det än är att veta exakt vad som hände, så kan man inte i egentlig mening skriva historien om "holocaust « utan att samtidigt reflektera över dess innebörd ${ }^{3}$.

Som bekant har historiska katastrofer också tidigare spelat en betydande roll inom judisk teologi. Jag vill påminna om det första templets fall år 586 före vår tideräknings början. Det var ju inte frågan om bara ett yttre skeende - förstörelse-exil-återvändande. Under exilen samlade man, tolkade och skrev ned de gamla traditionerna, som kom att utgöra den hebreiska bibeln. Toran blev normerande från Esras tid,
Profeterna och Skrifterna fick kanonisk status under de följande århundradena. Det som påskyndade och framtvang avslutningen av den hebreiska bibelkanon var i själva verket en ny katastrof, nämligen det andra templets fall är 70 efter vår tideräknings början. Under de följande århundradena skedde $\mathrm{i}$ sin tur samlingen och kodifieringen av Mishna, Gemara, Tosefta, Midrashim och Targumim, kort sagt den judiska traditionslitteraturen. En ny stor katastrof var utdrivningen frä Spanien air 1492. Även om den inte ledde till en litterär eller traditionsbevarande aktivitet jämförbar med de föregående, innebar den $i$ alla fall en fysisk spridning av den tusenåriga, högt utvecklade sefardiska judendomen till Italien, Holland, det ottomanska riket och t.o.m. det nyupptäckta Amerika. Denna katastrof kom också att förstärka de redan under medeltiden starkt utvecklade messianska förväntningarna, som kulminerade med sabbatianismen vid mitten av 1600-talet.

Om man vill kan man i den judiska historien upptäcka ett krismönster - svåra katastrofer utlöser reaktioner, som syftar till självbevarelse och överlevande inte bara i fysisk mening utan även i religiös. Det skedda måste ges en förklaring och därmed har man ställt det s.k. teodicéproblemet. Hur kunde Israels Gud tillåta, att denna olycka drabbade hans utvalda folk? De båda tempelförstörelserna tolkades vanligen så, att man sade »det är för våra synders skull «. Detta svar kunde tillgripas ännu efter utdrivningen från Spanien. Härtill kommer motivet om de messianska födslovåndorna: svåra hemsökelser skulle föregå Messias ankomst. De kunde tas som ett säkert tecken såsom fallet var i samband med Chmielnicki-massakrerna i Polen i mitten av 1600-tallet. 
Jag vill påminna om denna $\mathrm{i}$ och för sig välbekanta bakgrund till tolkningen av $\gg$ Holocaust «. Frågan är om detta gamla tolkningsmönster har varit användbart under andre hälften av det tjugonde århundradet. Jag får nöja mig med ett urval talesmän och ett urval av deras synpunkter.

\section{Richard L. Rubenstein}

utgav år 1966 en artikelsamling under titeln $A f$ ter Auschwitz, där han på sätt och vis sympatiserar med den s.k. radikala teologin, mera känd under devisen »God is dead «. Den »Gud《 som för Rubenstein är död, är »historiens gud «, för om det finns en sådan, så skulle han vara upphovsmannen till Auschwitz. ${ }^{4}$ Detta är en slutsats som Rubenstein kommit till genom sitt samtal med Oberkirchenrat Grüber i Berlin, som hävdade att det måste anses vara Guds vilja, att Hitler utrotade judarna. Det ligger enligt Rubenstein också helt $\mathrm{i}$ linje med de bibliska profeternas tolkning av historien och den s.k. judisk-kristna uppfattningen av Guds roll som herre över historiens lopp. ${ }^{5}$ Denna uppfattning måste emellertid överges efter Auschwitz, tillsammans med eskatologin. Rubenstein betraktar eskatologin som en sjukdom som döljer för människan det tragiska och hopplösa $i$ hennes öde. Därför kan han beteckna eskatologin som det kanske största misstaget judiskt tankeliv har frambragt. Det finns bara en "Messias« som kan frälsa mänskan ur ödets ironi, existensens smärtor och begränsningar. Och han kommer säkert: dödsängeln. Rubenstein anknyter till slutet av Isaac Bashevis Singers bok Familjen Moskat, där Hertz

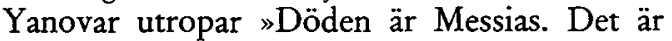
den verkliga sanningen ${ }^{6}{ }^{6}$ Den "Gud « Rubenstein för sin del kan tro på kallar han »The Holy Nothingness «, ur vilken vi kommer och till vilken vi återvänder. Denna gud kallas stundom även "Moder Jord «, som både framföder och slukar sina barn. ${ }^{7}$ Men ytterst förblir han/hon ett mysterium, den yttersta källan till vårt liv, men inte någon som man kan träda $i$ personlig relation till. ${ }^{8} \mathrm{Med}$ andra ord: Det traditionella sätten att interpretera katastroferna $\mathrm{i}$ den judiska historien är psykologiskt begripliga och har under tidigare förhållanden också tett sig meningsfulla. Efter Auschwitz kan vi inte längre tro på historiens Gud eller vänta på Messias. Livet kan ändå ges en mening på existentialistiskt vis, men en begränsad mening här och nu, ingen yttersta mening. En sådan viktig begränsad och inomvärldslig mening har t.ex. staten Israel. ${ }^{9}$

Rubenstein hänvisar till Kafka, Camus och Sartre. Detta gör också Maurice Friedman in sin bok To Deny Our Notbingness från 1967. Friedman är för övrigt starkt påverkad av Martin Buber och i slutet av boken lăter han även Elie Wiesel stå som exempel på en »dialog med det absurda«. Den som för en sådan dialog kan förliknas med Bibelns Job: »Denna dialog med det absurda innebär varken förnekelse eller bejakelse $i$ princip, utan att stå på sin post och möta vad som kommer med klarsynt förtröstan «. Den moderne Job måste liksom den bibliske ställa Gud till svars för den stora orättvisan i världen. ${ }^{10}$ Till detta kommenterar Rubenstein i sin följande bok The Religious Imagination (1968) att användningen av Job som modell är totalt förfelad: Det fanns (i Auschwitz) inte längre någon jobsfråga till $\mathrm{Gud}$, eftersom det inte fanns någon Job. "Job gick upp i rök. Och med honom hans fråga. «" ${ }^{11}$ Jag skall nu gå över till tänkare som mottagit kraftigare impulser av Wiesel.

\section{André Neher}

André Neber, den franske bibelforskaren, som år $1967 \mathrm{flyttade}$ till Jerusalem publicerade 1970 originalet till sin bok L'Exil de la Parole vilken $i$ år utkommmit i engelsk översättning. ${ }^{12} \mathrm{Ne}$ her försöker visa hur »tystnaden«, ibland »Guds tystnad «, ibland människors, spelar en utomordentligt viktig roll i Bibeln. Det är ju något som väcker förvåning för den som vant sig att betrakta »ordet « som det centrala, alltifrån skapelseordet till det ord profeterna tar emot och ger vidare. Jag skall här inte gå in på frågan huruvida Nehers analys är övertygande. Viktigare $\mathrm{i}$ sammanhanget är att han $\mathrm{i}$ synnerhet mot slutet av sin bok anknyter till vad han betraktar som det centrala begreppet hos Wiesel, nämligen just tystnaden. Han hänvisar till skillnaden i »landskap«: i Bibeln är det öknens tystnad, i Auschwitz är det isoleringens tystnad. Han visar hur Wiesel använder Aqeda-motivet avvikande från det bibliska ursprunget: här är det sonen som drar med sig fadern och här fullbordas offret faktiskt. ${ }^{13} \mathrm{Ne}-$ her hävdar, att Wiesel är mera konsekvent än Job, när det gäller att gå tillrätta med Gud. Hur skulle Jobs »nya« söner och döttrar kunna vara en kompensation för dem som dödats? Gud slipper undan för lätt. Om inte dialogen leder till något annat, måste den upphöra och 
ersättas av tystnaden. Människan får vända sig till sina dagliga göromål och inte lăta sig störas ens av messianska tankar. ${ }^{14}$

Till skillnad från Rubenstein tar inte Neber avstand fran Bibeln eller den judiska traditionen. Han framhäver i stället andra sidor av den, såsom rabbinska uttalanden som sätter den dagliga gärningen framom de messiansk förväntningarna. Eller som när han betonar tystnadens betydelse i förhållande till ordflödet eller dialogen. Här har han använt Wiesels romaner som nyckeln till sin förståelse av den judiska traditionen som inte kräver en hård och entydig förnekelse som hos Rubenstein.

\section{Emil Fackenheim}

Jag vänder mig nu till en annan av vår tids främsta interpreter av Auschwitz, som likaså starkt har influerats av Wiesel.

Emil Fackenheim, var själv internerad i arbetslägret i Sachsenhausen år 1938, men lyckades undkomma och är numera professor i filosofi i Toronto. Av hans arbete om »Holocaust « skall jag inskränka mig till en serie föreläsningar hållna 1968 och publicerade 1970 under titeln God's Precense in History. ${ }^{15}$ Fackenheim hävdar, att den gängse distinktionen mellan »religiösa« och »sekulariserade« judar idag måste ersättas av åtskillnaden mellan »icke-autentiska judar", som försöker undfly sin judiska identitet och »autentiska«, som bejakar densamma. Också nazisterna lät det bero på härstamning och inte på tro om man skulle räknas som jude eller inte. Fackenheim talar om »den befallande rösten från Auschwitz « och nämner fyra bud: ${ }^{16}$

1. att minnas och återberätta vad som hände;

2. att stiga ned från korset, ge upp martyrskapet och ställa livet framom döden;

3. att inte överlämna världen åt de krafter som åstadkom Auschwitz utan att fortsätta att arbeta och hoppas för världen;

4. för den »religiöse « att fortsätta brottningen med Gud och för den "sekulariserade" att åtminstone inte använda Auschwitz som ett ytterligare vapen mot honom.

Fackenheim är fullt på det klara med att dessa befallningar kommer att kollidera med varandra: hur kan man t.ex. minnas vad som hände utan att samtidigt förlora hoppet för världens framtid (1 och 3$)$ ? osv. Om världen ter sig för juden efter Auschwitz såsom en desperat plats att leva på, så blir den för alla människor allt mer en plats där ett universellt bolocaust kan äga rum i form av ett kärnvapenkrig. Juden kan här vara ett vittne om uthärdande av de konflikter och motsägelser som kraven att se världen sådan som den är och ändå arbeta och hoppas på den ställer oss inför. ${ }^{17}$

\section{Robert Alter}

Jag önskar här referera till den amerikansk-judiske litteraturhistorikern Robert Alter, som menar att Fackenheims överlevnadsteologi lyckas artikulera en vag men stark känsla hos stora delar av judenheten efter 1945. Oberoende av sina religiösa och ideologiska övertygelser har judarna känt en stark vilja att överleva som judar. Såsom kritik mot Fackenheim anför Alter dennes tendens att utsudda skillnaderna mellan »religiös « och "sekulariserad« på ett sätt som gör att också de sekulariserade judarnas beslutsamhet att förbli judar blir en form av "religiös avgörelse«. Alter menar, att det är karakteristiskt för den riktning som Wiesel och Fackenheim representerar, att det religiösa s.a.s. smyger sig in i det sekulära, på samma sätt som existentiella frågeställningar smyger sig in i den historiskt-vetenskapliga dokumentationen. ${ }^{18}$

Detta sistnämnda blir kanske klarare om vi vänder oss till en tredje representant för denna riktning, nämligen ledaren för Holocaust Resource Center vid City University New York, nämligen

\section{Irving Greenberg}

Med hänvisning til Wiesel uppställer han följande princip: »Ingen teologisk eller annan utsaga borde göras som inte vore trovärdig med hänsyn till de brinnande barnen « dvs. i Auschwitz. ${ }^{19}$ Han hävdar, att vare sig den klassiska teismen eller ateismen är kapabla att infoga denna händelse i någon acceptabel eller definitiv modell. Han hyser stor förståelse t.ex. för Richard L. Rubensteins position - nämligen att förkasta den traditionella judisk-kristna teismen - men anser att hans ateistiska slutsatser är för snabba och tvärsäkra. ${ }^{20}$ Själv utvecklar han en dialektik, som går ut på att Auschwitz gör det till en moralisk nödvändighet att räkna med ett liv efter detta, en uppståndelse, en tillkommande värld. ${ }^{21}$ Men detta är ingen teodicé, försvar för eller upprättelse av Gud i vanlig mening. Greenberg tar upp tre bibliska modeller: Job, den lidande Tjänaren och Klagov. 3. för att se om och hur de kan hjälpa oss vidare: ${ }^{22}$ 
1. De teologiska implikationerna av Job skulle vara att förkasta varje lättvindig förtröstan eller förnekelse men behålla en dialektisk förväntan på framtida uppenbarelser av den gudomliga närvaron. Här vill Greenberg betrakta den pånyttfödda staten Israel som ett tungt vägande vittnesbörd.

2. Jes 53 läter som ett stycke "holocaust «-litteratur och Greenberg vill betrakta behandlingen av den lidande tjänaren (= det judiska folket) som ett tidigt alarmsystem för de faror som en bestämd kultur kan hysa. På samma sätt är »Holocaust« ett alarmsystem för den västerländska kulturen. Man behöver bara föreställa sig att Hitler skulle ha kommit till makten 1963 i.st.f. 1933: vätebomben hade då resulterat $i$ en världsomfattande holocaust.

3. I Klagov. 3 läser vi bl.a. "Han har uppfrätt mitt kött och min hud, han har krossat benèn i mig « (v. 4). Kap. får en omsvängning till förtröstan i v. 22. Greenberg menar att detta är också Elie Wiesels tema och att dess implikationer är att varken rättfärdiga människor eller Gud, att fullständigt rannsaka sig själv och utrensa alla illusionära förestälningar om oss själva och Gud. Det kan innebära att vi träder in i en period av tystnad om Gud som motsvaras av hans egen tystnad. I denna tystnad kan Gud vara närvarande och föremål för hopp, men inte en deus ex machina. ${ }^{23}$

Det finns emellertid ett centralt religiöst vittnesbörd också $\mathrm{i}$ denna situation och det är det mänskliga livets eget vittnesbörd: att bejaka livets meningsfullhet, dess värde genom att ge kärlek och skapa liv. Om nämligen människan är Guds avbild, men det är omöjligt att göra utsagor om Gud själv efter Auschwitz, så bör vi àterupprätta avbilden. Här nämner Greenberg igen staten Israel som en fundamental akt av àterskapande av liv och mening för det judiska folket. Men vi skall inte stanna vid denna akt utan gå vidare till att återupprätta andra förtryckta folk och folkgrupper. Ingen borde längre få vara beroende av någon annans goda vilja eller någon annans respekt för lag och rätt. Holocaust visar att alla som har makt kan svika och därför är en radikal och fortgående omfördelning av makten ett måste både ur religiös och etisk synpunkt. Greenberg vill alltså inte ge oss några enkla lösningar utan bevara dialektiken, spänningen. ${ }^{24}$

Liksom $\mathrm{i}$ fråga om Fackenheim kan man med Robert Alter invända mot detta att Auschwitz blir en mycket svä fixering om det skall vara proberstenen för allt vad som är genuint judiskt eller över huvud värt att bevara. Man kan ifrågasätta om staten Israel så entydigt kan eller bör ses mot bakgrunden av Auschwitz: både dess positiva och negativa sidor hade förmodligen varit desamma också utan ett »Holocaust《. Problemen med arabstàterna hade funnits; frågan är om inte holocaust-temat har en negativ inverkan på alla försök att komma till ett modus vivendi mellan judar och araber. ${ }^{25}$

\section{Arthur A. Cohen}

Jag skall avsluta denna parad av judiska teologer med amerikanen Arthur A. Coben, känd som författare till skönlitterära, filosofisk-teologiska verk och utgivare av antologier över judiskt tänkande. Cohen lånar Rudolf Ottos term tremendum därför att "Holocaust « är en realitet eller verkning som inte kan härledas endast ur vad som en historiker skulle kunna betrakta som dess orsaker. Ingen beskrivning av det med termer som mord, barbari, grymhet eller sadism räcker till, inte ens vad man kallat »det absoluta onda«. Enkelt uttryckt kan man säga, att dödslägren byggdes för att uppfylla ett enda mål: att döda det största möjliga antalet judar till den minsta möjliga kostnad ifràga om pengar och material. I anslutning till Yosef Hayim Yerushalmi påpekar Cohen, att den kristna kyrkan under medeltiden mycket väl hade kunnat åstadkomma det. Orsaken till att så inte skedde är, att kyrkan var ambivalent ifråga om judarna: hon kunde inte skära av sina rötter trots att hon förkastade den judiska tron på samma sätt som kättarnas - och det blev judarnas räddning. ${ }^{26}$

Men det tremendum som Cohen här talar om är ett mänskligt sådant inte ett gudomligt mysterium tremendum. Dödslägren är ett monument över en meningslös perversion av livet till en orgiastisk hyllning av döden. Och detta mot ett folk som fäst större vikt vid att välja livet, förbättra det genom religiös-etisk fostran än något annat $i$ västerlandet. Också Cohen anser att alla hittillsvarande teologisk-filosofiska konceptioner var otillräckliga: Martin $\mathrm{Bu}-$ bers tal om "gudsförmörkelse«, Rubensteins och andras tal om »Guds död " och t.o.m. Nietzsches supermänniska som tar över efter Guds död. I den judiska historien har - som redan nämnts - inträffat händelser som kan be- 
tecknas såsom djupa gap eller klyftor, men man har alltid lyckats överbrygga dem. Cohen sällar sig till Fackenheim, Greenberg och andra när han menar, att detta sista gap inte kan överbryggas på något av de traditionella sätten: då levde man i medvetande om mysterium tremendum, Israels Gud. Nu finns det enligt Cohen ingen möjlighet att gå över klyftan vare sig med skuld eller med hopp. I stället måste man stiga ned i den så djupt man förmår för att utforska det demoniska, för att lära känna det och varna världen för detta. ${ }^{27}$

Cohen hänvisar till det judiska påskmotivet, att varje jude skall betrakta sig såsom en som var med om uttåget från Egypten - som verkligen om inte bokstavligen var med. På samma sätt skall han betrakta sig som deltagare i förbundsslutandet på Sinai. Och så skall han slutligen betrakta sig såsom verkligt närvarande $i$ dödslägren även om det bokstavligen inte skulle vara sant. Han måste höra vittnesbörden därifrån för att själv kunna avlägga vittnesbörd därom. Därför måste också motivet om Israels närvaro $i$ dödslägren få inträde $i$ liturgin - precis såsom uttåget ur Egypten. Hopp och förtvivlan är också för Cohen ett dialektiskt ordpar som inte får skiljas åt. ${ }^{28}$

Robert Alters kritik träffar Cohen på samma sätt som Greenberg: vi kan visserligen inte utplåna ur vårt medvetande vad som hände, men vi har rätt att ge vidare åt våra barn vadhelst som vi betraktar som värdefullt $i$ den judiska traditionen utan att ständigt pröva det $i$ det mörka glaset från Auschwitz. Här citera Alter Jacob Neusners uttalande: »Faktum är att de levande lever. Valet gäller framtiden, inte det förflutna ${ }^{29}$

\section{Sammanfattning}

En kort sammanfattning av problematiken kan formuleras så här:

1. teodicéproblemet kan inte lösas på traditionellt sätt. Antingen måste vi radikalt revidera vår gudsuppfattning, såsom Rubenstein, eller så måste vi avstå från varje försök till teodicé.

2. I stället kan man försöka sig på en dialektik mellan Exodus/Sinai à ena sidan och Auschwitz å den andra, såsom de flesta av de Wieselinfluerade teologerna gör. Det kan innebära tystnad eller tigande.

3. Viktigare än att anklaga Gud är slutligen att anklaga människan. Holocaust är ett vittnesbörd om den västerländska civilisatio- nens sammanbrott och det bedrägliga att sätta sin tilltro till någon ideologi.

\section{Anmärkningar:}

1. Holocaust, 1978.

2. Le dernier des Justes, Paris 1959, svensk övers. Bonniers 1960.

3. Arthur A. Cohen, The Tremendum: Some theological implications of the Death camps, i Forum on the Jewish People, Zionism and Israel, No 30-31, $1978,121 \mathrm{f}$

4. After Auscbwitz, Indianapolis etc., 1966, 204.

5. Ibid., 65.

6. Ibid., 260.

7. Ibid., 202, 258.

8. Ibid., $239 \mathrm{f}$.

9. Richard L. Rubenstein, The Religious Imagination, A study in Psychoanalysis and Jewish Religion, Indianapolis etc., 1968, 168 och dens., Power Struggle, New York 1974, $192 \mathrm{f}$.

10. To deny our Notbingness, London 1967, 348-353.

11. The Religious Imagination, XVIII/XIX.

12. L'Éxil de la Parole, Paris 1970. Jag hänvisar i det följande till den engelska översättningen The Exile of the Word. From the Silence of the Bible to the Silence of Auschwitz, Philadelphia 1981.

13. Ibid., $216 \mathrm{ff}$.

14. Ibid., $177 \mathrm{f.}, 188 \mathrm{ff}$.

15. God's Precense in History. Jewish Affirmations and Philosophical Reflections, New York - London 1970.

16. Ibid., $84 \mathrm{ff}$.

17. $I b i b ., 89 \mathrm{ff}$.

18. Deformations of the Holocaust, Commentary, 71:2 (Febr. 1981), 53.

19. Cloud of Smoke, Pillar of Fire: Judaism, Christianity, and Modernity after the Holocaust, i Eva Fleischner (utg.), Auschwitz: Beginning of a New Era?, New York, 23.

20. Ibid., $26 \mathrm{ff}$.

21. Ibid., $29 \mathrm{f}$.

22. Ibid., $34 \mathrm{ff}$.

23. Ibid., 41.

24. Ibid., $44 \mathrm{ff}$.

25. Alter, op. cit., 52.

26. Cohen, op.cit., $125 \mathrm{ff}$.

27. Ibid., $129 \mathrm{ff}$.

28. Ibid., $128 \mathrm{f}$.

29. Alter, op.cit. 54. Jag kan hänvisa till Neusners nyutkomna bok Stranger at Home, "The Holocaust «, Zionism, and American Judaism (University of Chicago Press 1981), som jag själv ännu inte hunnit ta del av men som enligt förhandsinformationen kallar sammenkopplingen av sholocaust « och staten Israels uppkomst »the myth of the Holocaust and Redemption $\kappa$.

\section{Holocaust-temat inom kristen teologi - några anmärkningar}

Trots att Holocaust-temat har varit av primärt intresse för den judiska teologin, har det av lätt 
förståeliga skäl inte heller kunnat undgå att sätta spår inom kristen teologi, särkilt på kontinenten och i USA.

Dialogen mellan kristna och judar som fick en trevande början redan före andra världskriget och som återupptogs några år efter krigssluten har intensifierats på mycket anmärkningsvärt sätt. Kristna teologer har förstått också utan att judarna har måst tala om det att den 1900 år långa gemensamma historien innehåller mycket sådant som bidragit till att bereda jordmånen för dödslägren:

1. den s.k. undervisningen i förakt är något betydligt ödesdigrare än de faktiska motsättningar som råder mellan kristen och judisk teologi. Medveten om sina judiska rötter gjorde kyrkan redan i gammal tid inte bara anspråk på att vara arvtagaren av löftena, vilket demonstrerades genom skrifbevis. Andra templets fall och judendomens förnedring inom det romerska riket togs som ett synligt bevis på att synagogan var förkastad av Guds själv. När sedan kristendomen blev statsreligion, kom den att stegvis underminera den status som religio licita som judendomen åtnjutit i det romerska riket. Kyrkofäder såsom Ambrosius och Krysostomos kom att använda sin auktoritet och vältalighet till utmåla judarna såsom Guds fiender och ifrågasätta deras rätt att verka och leva i det kristna samhället. Högmedeltiden uppvisar sedan en lång serie av vidskepliga anklagelser för hostieskändningar, rituella mord, brunnsförgiftning, ocker, vilka i sin tur ledde till tvångsdop, massmord $i$ samband med korstågen, utdrivningar ur länder som Spanien där judendomen hade levat och frodats $i$ tusen år. Ghettona var också en av romerska kyrkan påtvungen inrättning. Polemiken mot judarna fortsatte inom reformationen. Sentida massakrer återupptogs i Polen och Ryssland o.s.v. Skulle hela denna dystra krönika ha kunnat undgå att bereda vägen för nazisternas "Endlösung der Judenfrage«?

2. De flesta kristna teologer anser att det finns ett klart samband. Men därmed är ännu inte sagt att kristendomens långa antijudiska hållning är huvudorsaken, som direkt leder till Holocaust. Det finns teologer som hävdar detta (t.ex, katoliken Rosemary Radford Ruetber). Andra hävdar ett mera indirekt samband, som går ut på att den religiösa antagonismen avlöstes av de sekulära rasteorierna under andra hälften av 1800-talet vilka. bland annat byggde på en sammanblandning mellan frågor om språk och ras så att indogermansk och arisk likställdes. Även om denna senare förklaring nog får anses riktigare, kvarstår dock såsom något ofrånkomligt, att här finns ett samband och att den rasistiskt inriktade nazismen kunde bygga på och anföra de gamla djupt rotade religiösa resentimenten mot judarna.

3. Detta har fört med sig att kyrkornas representanter har haft en en mycket tung skuldbör$d a$ i sitt förhållande till judarna. Det har blivit nödvändigt att gå till rätta med kyrkornas förflutna, innan man har kunnat vända sig till frågor som rör framtiden. Det är svårt att avgöra hur hälsosamt detta nya sätt att läsa kyrkohistoria har varit. Men det är intressant att se hur man på judiskt håll har reagerat: somliga säger, att kyrkan förlorade all sin trovärdighet genom Auschwitz, eller rent av att kristendomen dog $\mathrm{i}$ Auschwitz. Andra åter säger att det visserligen är viktigt att ta reda på vad som har hänt och erkänna fakta, men att det inte finns någon anledning att bekänna mea culpa idag. Lika litet som judarna själva idag kan vidkännas den gamla beskyllningen för att vara gudsmördare, skulle dagens kristna som träder i dialog och samarbete med judarna betrakta sig som mördare.

4. Slutsatserna kunde bli för de kristna liksom för judarna, att det nu är viktigt att se framät mot de gemensamma faror och uppgifter som kristna och judar har: de totalitära ideologierna, rasdiskrimineringen, krig, flyktingproblem, svält - här finns enorma utmaningar och möjligheter till insatser på att ett nytt Holocaust måtte kunna avvärjas.

Testamentet tillhör alltså de kristne och icke längre judarna, som har blivit förkastade genom att de har förkastat Kristus.

En förändring på denna punkt är detta, dels at man menar, att det finns en anti-judaism i själva Nya testamentet, att man öppet erkenner, att det finns vissa nytestamentliga skrifter som innehåller anti-judiska uttalan- 
den, Johannes-evangeliet, till exempel. Men dels också detta, att man inte längra citerar det här med att Israel var det tidigare gudsfolket, de kristna det nuvarande, utan att man taler om de tvă gudsfolken, de kristna och judarne. Man menar att de visseligen inte har gåt samman, att de kanske inte kommer att gå samman, - men att de står sida vid sida och vittnar om olika sidor av samma ursprungliga judiska arv.

Det tredje synpunkt, som jag kunde nämna, och som jag inte vet hur långt man har kommit med, reser ett problem för de kristna: är Holocaust en händelse, som på något sätt kann jämställas med Golgata inom den kristna teologin? Kann man av en negativ tilldragelse göra nogàt positivt? Det kan man $\mathrm{i}$ viss mån inom den judiska teologin, nämligen så att Holocaust hos vissa judiska teologer efterföljs av och förbinds med staten Israels uppkomst. Jag vill inte ta ställning till om detta är en framkomlig veg. Men kärnan i detta att Jesus var Jude, att han korsfästes och samtidigt med honnom många andra Judar. Något liknande upprepades i Holocaust, vilket antyds $\mathrm{i}$ boktiteln "The Crucifixion of the Jews «.

\section{BOKLISTA:}

\section{Judisk teologisk Holocaustlitteratur i urval:}

Alter, Robert: Deformations of the Holocaust. Commentary 71:2 (Febr. 1981): s. 48-54

Berkovits, Eliezer: Faith after the Holocaust. KTAV: New York 1973

Coben, Arthur A.: The Tremendum: a Theological Interpretation of the Holocaust. The Crossroad Publ. Co.: New York 1981

Ezrabi, Sidra D.: By Words Alone. The Holocaust in Literature. University of Chicago Press: Chicago 1980.

Fackenbeim, Emil L.: God's Precense in History. Jewish Affirmations and Philosophical Reflections. New York University Press New York/ University of London Press: London 1970

- Encounters between Judaism and. Modern Philosophy. A Preface to Future Jewish Thought. The Jewish Publication Society of America: Philadelphia 1973.

- The Jewish Return into History. Reflections in the Age of Auschwitz and a New Jerusalem. Schocken: New York 1978.

Greenberg, Irving: Cloud of Smoke, Pillar of Fire: Judaism, Christianity and Modernity after the Holocaust, ingair i Fleischner, Eva (utg), Auschwitz: Beginning of at New Era? Reflections on the Holocaust. KTAV: New York 1980, s. 7-55.

Kogon, Eugen m.fl.: Gott nach Auschwitz. Dimensionen des Massenmordes am jüdischen Volk. Herder Verlag: Freiburg 1979.

Neber, André: L'Exil de la Parole. Paris 1970. Engelsk oversättning: The Exile of the Word. From the Silence of the Bible to the Silence of Auschwitz. JPS: Philadelphia 1981.

Neusner, Jacob: Stranger at Home. »The Holocaust «, Zionism and American Judaism. Chicago University Press: Chicago 1981.

Rosenfeld, Alvin H. och Irving Greenberg (utg.): The Impact of Elie Wiesel. Indiana University press Indiana/Bloomington: London 1979.

Richard L. Rubenstein: After Auschwitz. Indianapolis etc 1966. The Religious Imagination. A Study in Psychoanalysis and Jewish Religion. Indianapolis etc 1968.

- Power Struggle. New York 1974.

- The Cunning of History. The Holocaust and the American Future. Harper \& Row: NY 1975
Kristen teologisk Holocaustlitteratur i urval:

Buren, Paul $M$. van: Discerning the Way. A Theology of the Jewish-Christian Reality. Seabury Press: New York 1980.

Davies, Alan T. (utg): Antisemitism and the Foundations of Christianity. Paulist Press: New York, Ramsey, Toronto 1979.

Eckert, Willehad Paul och Ebrlich, Ernst-Ludwig (utg.): Judenhass - Schuld der Christen?! Hans Driewer Verlag: Essen 1964

Erklärung über das Verhältnis der Kirche zum Judentum. Sekr. der Deutschen Bischofskonferenz, Bonn 1980.

Fleischner, Eva (utg.): Auschwitz: Beginning of A New Era. Reflections on the Holocaust. KTAV: New York 1977.

Littel, Franklin H.: The Crucifixion of the Jews. Harper \& Row: New York 1975.

Marsch, Wolf-Dieter och Thieme, Karl. (utg.): Christen und Juden. Ihr Gegenüber vom Apostelkonzil bis heute. Matthias Grünewald-Verlag: Mainz/Vandenhoeck \& Ruprecht: Göttingen 1961

Pawlikowski,John D.: The Callenge of the Holocaust for Christian Theology. Anti Defamation League: New York 1978.

Rendtorff, Rolf (utg.): Arbeitsbuch Christen und Juden. Zur Studie des Rates der Evangelischen Kirche in Deutschland. Gütersloher Verlagshaus Gerd Mohn: Gütersloh 1979.

Ruether, Rosemary Radford: Faith and Fratricide. The Theological Roots of Antisemitism. Seabury Press: New York 1974.

Simon, Ulrich: A Theology of Auschwitz. SPCK: London 1978.

Thieme, Karl (utg.): Judenfeindschaft. Darstellung und Analysen. Fischer Bücherei 524. Frankfurt a. M., Hamburg 1963.

Thoma, Clemens: Christliche Theologie des Judentums. Paul Pattoch Verlag: Aschaffenburg 1978.

Zuidema, Willem: Akeda - Isaak wird wieder geopfert. Neukirchener Verlag: Neukirchen 1981.

- Gottes Partner - Begegnung mit dem Judentum. Neukirchener Verlag: Neukirchen 1980.

Zur Erneuerung des Verhältnisses von Christen und Juden, ingår $i$ Handreichung für Mitglieder der Landessynode, der Kreissynoden und der Presbyterien der evangelischen Kirche im Rheinland: Nr. 39. 1980. 